\title{
Finding the optimal vertical distribution: behavioural responses of Daphnia pulicaria to gradients of environmental factors and the presence of fish
}

\author{
PETTER LARSSON AND WINFRIED LAMPERT \\ Max Planck Institute for Evolutionary Biology, Plön, Germany
}

\section{SUMMARY}

1. The vertical distribution of zooplankton results from active habitat choice aiming to optimise fitness gain in a system of trade-offs.

2. Using large, controlled indoor mesocosms (Plön Plankton Towers), we monitored the behavioural response of Daphnia pulicaria to vertical gradients of temperature, food, oxygen and light, in the presence and absence of fish predation.

3. In the absence of fish, Daphnia distributed as predicted by an ideal 'free distribution with costs'. If the food was distributed homogeneously, they stayed in the warm epilimnion, while they balanced their time dwelling in epi- and hypolimnion if the food was concentrated in a deep-water maximum.

4. However, oxygen depletion in the hypolimnion, representing an additional cost, prevented Daphnia from completely exploiting the hypolimnetic food maximum. Consequently, the proportion dwelling in the hypolimnion was larger if oxygen was not limiting.

5. Fish predation had an overwhelming effect, driving Daphnia into the hypolimnion under all experimental conditions. If permitted by oxygen availability, Daphnia used the whole hypolimnion, but oxygen depletion reduced their possible habitat to the upper hypolimnion with oxygen concentrations above c. $0.7 \mathrm{mg} \mathrm{L}^{-1}$. As fish were less tolerant of low oxygen, the layer below the thermocline formed a predation refuge for Daphnia.

Keywords: Daphnia, environmental gradients, fitness optimisation, predation, vertical distribution

\section{Introduction}

Stratified lakes show characteristic vertical patterns of environmental factors, mostly based on the different vertical gradients of light and temperature (Lampert \& Sommer, 2007). Theory predicts that the vertical distribution of zooplankton in a stratified waterbody is the result of active habitat choice to optimise fitness. Zooplankton must often find compromises for trade-offs in factors enhancing or decreasing fitness. If these factors change, zooplankton must respond with changes in their vertical distribution. This response has been described best as diel vertical migration controlled by light conditions in the epilimnion, either indirectly affecting visual fish predation (Lampert, 1993) or directly through damaging UV radiation (Williamson et al., 2011).
Environmental factors affecting the fitness of filterfeeding zooplankton exhibit different vertical profiles. The intensity of light-dependent factors (visual predation, UV damage) decreases exponentially with depth, following the decrease in light. Hence, the vertical profiles are affected by water transparency. In contrast, temperaturedependent (i.e. stratification-dependent) factors rather exhibit discontinuous vertical profiles affected by the two-layer system, the warm, mixed epilimnion and the cold hypolimnion connected by a steep gradient (thermocline). Air temperature and wind control the vertical temperature profile, the difference between the layers and the steepness of the thermocline. Temperature is itself a strong factor that affects fitness through metabolism and development. Algal and bacterial food sources can be homogeneously distributed in the epilimnion or show a

Correspondence: Petter Larsson, Department of Biology, University of Bergen, Postbox 7803, N-5020 Bergen, Norway.

E-mail: petter.larsson@bio.uib.no 


\section{P. Larsson and W. Lampert}

deep-water maximum related to the thermocline. Oxygen can be an important factor in productive lakes if the hypolimnion becomes gradually oxygen-depleted. Severe oxygen depletion can determine the lower boundary of the vertical distribution of zooplankton.

The vertical profile of habitat suitability, being affected by all environmental factors, can be rather complex because of the differing shapes of the individual profiles (Winder, Spaak \& Mooij, 2004). A simplified conceptual model, restricted to effects of temperature and food availability, has been presented by Lampert, McCauley \& Manly (2003). Their experimental results supported the hypothesis that Daphnia distributed according to an ideal free distribution (IFD) with costs (Tyler \& Gilliam, 1995), although not all the conditions of the IFD model were met. However, field distributions are more difficult to interpret as they are shaped by additional costs, such as the trade-off between food availability and fish predation risk (Leibold, 1990; Dini \& Carpenter, 1992). Fish predation is a particularly strong factor shaping vertical distributions (Ringelberg et al., 1991; Lampert, 1993), and its dependence on light intensity and prey size causes variations of distributions in lakes of varying transparency (Dodson, 1990; Williamson et al., 2011) and of differently sized species (Leibold \& Tessier, 1991). Oxygen depletion is usually most pronounced near the bottom of a lake; hence, it shifts the possible habitat of zooplankton (except Chaoborus larvae) upwards (Tessier \& Leibold, 1997). However, various zooplankton, in particular cladocerans, have been shown to tolerate lower oxygen concentrations than planktivorous fish do. This can create a refuge for zooplankton at the boundary where oxygen is low but hydrogen sulphide (being produced under anoxic conditions and toxic at low concentrations) is not yet important (Hanazato, Yasuno \& Hosomi, 1989; Vanderploeg et al., 2009; Larsson \& Lampert, 2011). Under such conditions zooplankton can accumulate below the thermocline despite the costs of low temperature, low oxygen concentration and possibly poor food conditions.

Daphnia have proved particularly useful for studying the mechanisms and causes of vertical habitat choice (Lampert, 2011). As it is difficult to perform such experiments under controlled field conditions (even in deep enclosures), the large-scale indoor system (Plön Plankton Towers) that provided full control over the vertical structure of the water column (Lampert \& Loose, 1992) was frequently used to study the effects of individual factors and trade-offs on the distribution of Daphnia, including trade-offs between temperature and food (Lampert et al., 2003; Kessler \& Lampert, 2004a), effects of body size (Kessler \& Lampert, 2004b) and population density on this trade-off (Lampert, 2005), food quality (Reichwaldt \& Abrusan, 2007; Reichwaldt, 2008), predation by visually hunting fish and light (Loose, 1993; De Meester, Weider \& Tollrian, 1995) and food versus temperature tolerance (Havel \& Lampert, 2006).

We used the Plankton Tower system to study the behavioural response of a relatively large Daphnia species, Daphnia pulicaria Forbes, to the simultaneous action of various environmental factors (temperature, food, fish predation and oxygen concentration) and to estimate the relative importance of these factors. Our hypothesis was that the vertical distribution of Daphnia is the result of optimising fitness under the additive effect of changing environmental factors.

\section{Methods}

\section{Experimental design}

Experiments were performed with a clone of D. pulicaria that has been cultured in the laboratory for two decades after it was isolated from a carp pond in Southern Germany. This clone was known to respond to fish kairomones by diel vertical migration. We used the Plön Plankton Towers, a system of two stainless steel indoor mesocosms that were $11.5 \mathrm{~m}$ high and had an inner diameter of $86 \mathrm{~cm}$ (Lampert \& Loose, 1992). This system had a stable temperature control with vertical resolution, which allowed the construction of vertical profiles of temperature, algae and chemical conditions. Zooplankton could be sampled through ports at c. $50 \mathrm{~cm}$ vertical distance in pump-driven traps (Lampert \& Loose, 1992). Experiments followed the basic design described in Lampert et al. (2003). The two towers were run in parallel, and they were used as replicates. The water column was thermally stratified to form three layers separated by thermoclines, the warm epilimnion $\left(20^{\circ} \mathrm{C}, 0-2.5 \mathrm{~m}\right)$, the cool hypolimnion $\left(10^{\circ} \mathrm{C}, 2.5-5.5 \mathrm{~m}\right)$ and the deep layer $\left(7.5^{\circ} \mathrm{C}, 5.5 \mathrm{~m}\right.$ to the bottom). The second thermocline was necessary to establish a stable hypolimnetic algal maximum. As no live Daphnia were found below the second thermocline, we consider only the nine ports sampled in the upper two layers (Fig. 1). Large lamps above each tower provided light at a diel cycle of $12 \mathrm{~h}$.

We performed three successive experiments under identical temperature conditions but differing in vertical gradients in algal food (Scenedesmus obliquus Meyen) and oxygen concentration (Fig. 2). Experiments (expts.) 1 and 2 created a low-oxygen hypolimnion, while the water column was oxygen saturated to the bottom in expt. 3 . In expts. 1 and 3, food was abundant in the hypolimnion but 


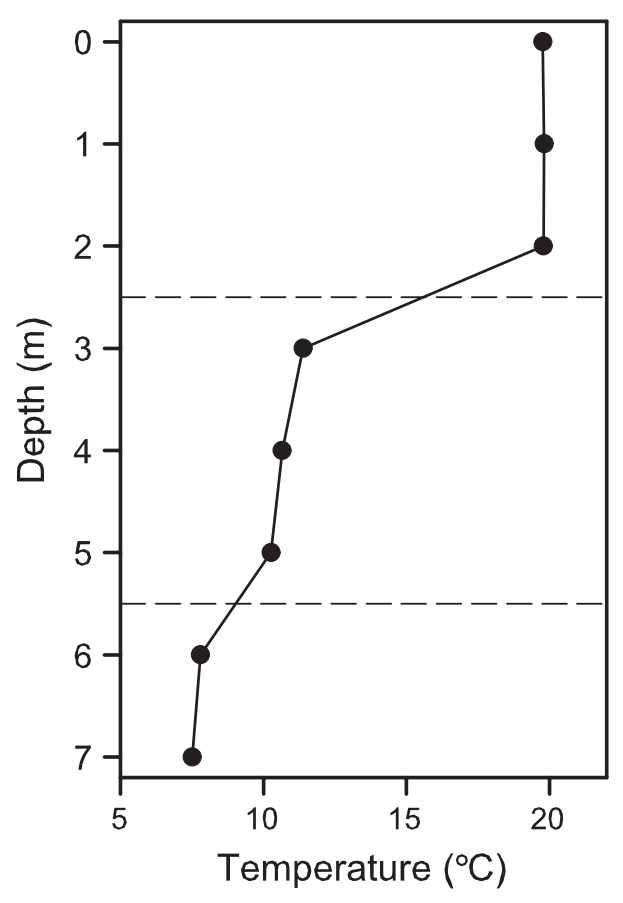

Fig. 1 Temperature profile combined from all sampling dates for both towers and all three experiments (mean $\pm \mathrm{SE}, n=36$ ). Values of the error bars are too small to be visible. The horizontal broken lines indicate the thermoclines.

very low in the epilimnion, while epilimnion and hypolimnion had high food concentrations in expt. 2. Thus, in the absence of fish, Daphnia had to trade food against low temperature plus hypoxia in expt. 1 and only against low temperature in expt. 3, while there was no trade-off in expt. 2. The vertical distributions of Daphnia were monitored in the absence and in the presence of fish in all experiments.

\section{Set-up and sampling}

Detailed descriptions of the culture of Daphnia and Scenedesmus, the creation of the oxygen gradient, light conditions, the maintenance of algal distributions, the procedure of Daphnia sampling, as well as of the counting and sizing of D. pulicaria are given in Larsson \& Lampert (2011). In short, Daphnia and Scenedesmus were grown in large batches in the laboratory. Towers were filled with filtered $(5 \mu \mathrm{m})$ lake water from the nearby Schöhsee. The upper thermocline was first established, and then oxygen was removed from the water below $2.5 \mathrm{~m}$ using an airlift system with pure nitrogen for $24 \mathrm{~h}$. Only then was the second thermocline established. The airlift system has also been described in detail in Larsson \& Lampert (2011). Vertical gradients of temperature and oxygen were monitored daily with probes lowered from the water surface. Concentrated algal food was added to the appropriate depth by a tube. Vertical profiles of the actual algal concentration in the towers were measured by a particle counter (CASY, Schärfe) every morning, and algal losses owing to grazing and sedimentation were replaced. Food concentrations were kept above the incipient limiting concentration (ILC, c. $0.4 \mathrm{mg} \mathrm{C} \mathrm{L}^{-1}$ ) of D. pulicaria, or they remained far below the ILC (Fig. 2). Daphnia were sampled in glass traps from $48 \mathrm{~L}$ of water each, at nine depths and from both towers simultaneously.

After the set-up of the conditions, the mesocosms were inoculated with D. pulicaria and the populations were left to grow for about 2 weeks to build up a reasonable population before sampling started. Zooplankton samples were taken in the morning $c .3 \mathrm{~h}$ after light-on approximately every other day. In addition, night samples $(3 \mathrm{~h}$ after light-off) were taken in expts. 2 and 3 at the same dates as the day samples (23 profiles) to test for light effects (diel vertical migration). Unfortunately, we did not sample at night in expt. 1 as we expected the very low densities of food particles in the epilimnion to prevent diel vertical migration (Johnsen \& Jakobsen, 1987). After a minimum of three sampling dates, both towers were stocked each with five small cyprinid fish (Leuciscus idus; length, 46-76 mm; weight, c. 2-4 g). The light colour of these fish made it possible to count them from above, and dead fish were replaced when necessary. The first Daphnia samples in the presence of fish were taken 1 day after fish introduction. Successive samples were taken daily or after 2 days, depending on the velocity of the Daphnia density reduction owing to fish predation (Larsson \& Lampert, 2011).

\section{Sample processing}

Zooplankton samples were preserved in sucrose formaldehyde (Haney \& Hall, 1973). They were later counted and sized by the bench-top version of the Optical Plankton Counter (Focal Technologies, Darthmouth, NS, Canada). The suitability of this method for counting monospecific Daphnia had been tested beforehand (Kessler \& Lampert, 2003). Daphnia were assigned to four body size classes $(0.6-1.0 \mathrm{~mm}, 1.01-1.5 \mathrm{~mm}, 1.51-2.0 \mathrm{~mm}$ and 2.01-3.5 mm). The first two classes were grouped as 'small' and the second two classes as 'large'.

The analyses were performed using the last three sampling dates before fish introduction (pre-fish) and the first three sampling dates after fish introduction (postfish). Each date consisted of two vertical profiles (towers) except on the third post-fish date in expt. 2. Only one profile was available for this date as the Daphnia density in 
Expt. 1
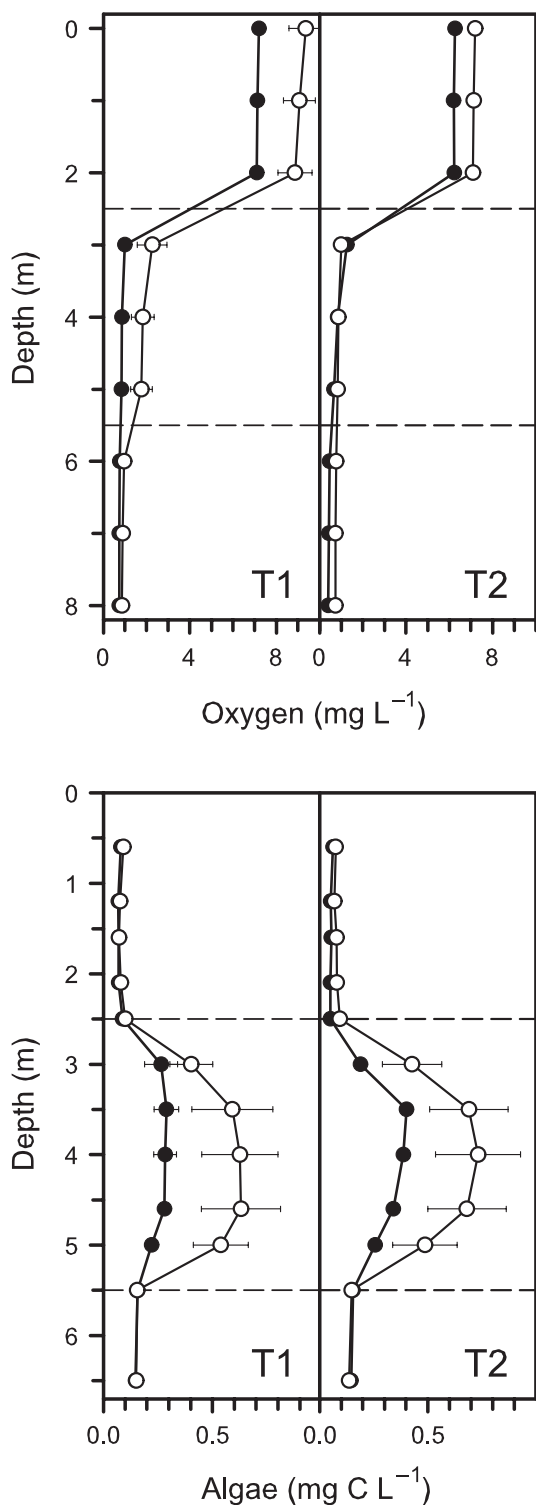

Expt. 2
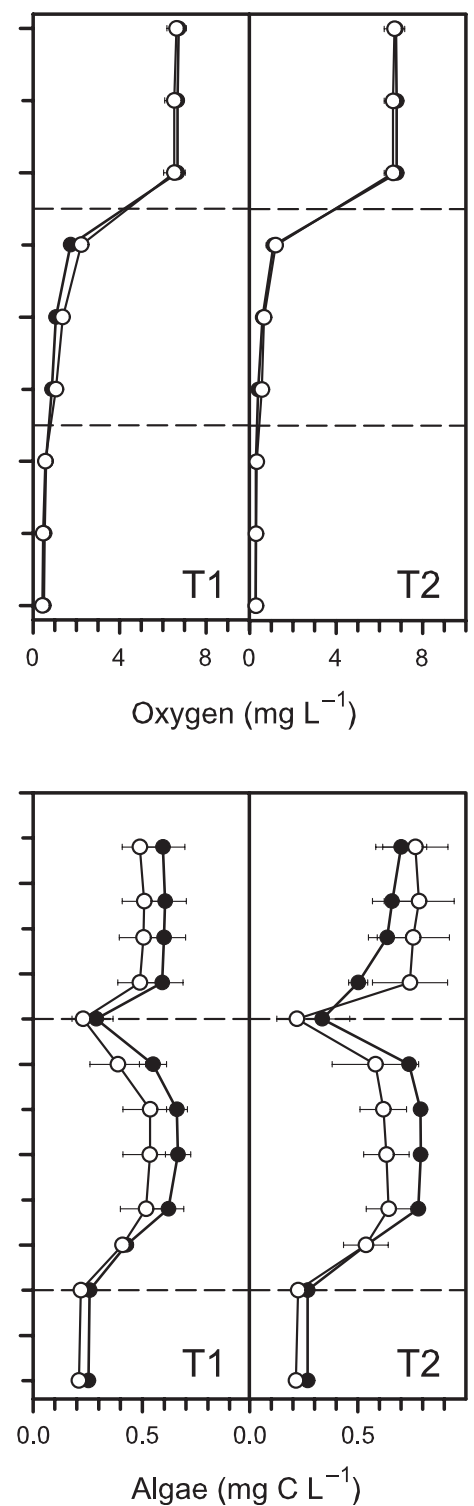

Expt. 3
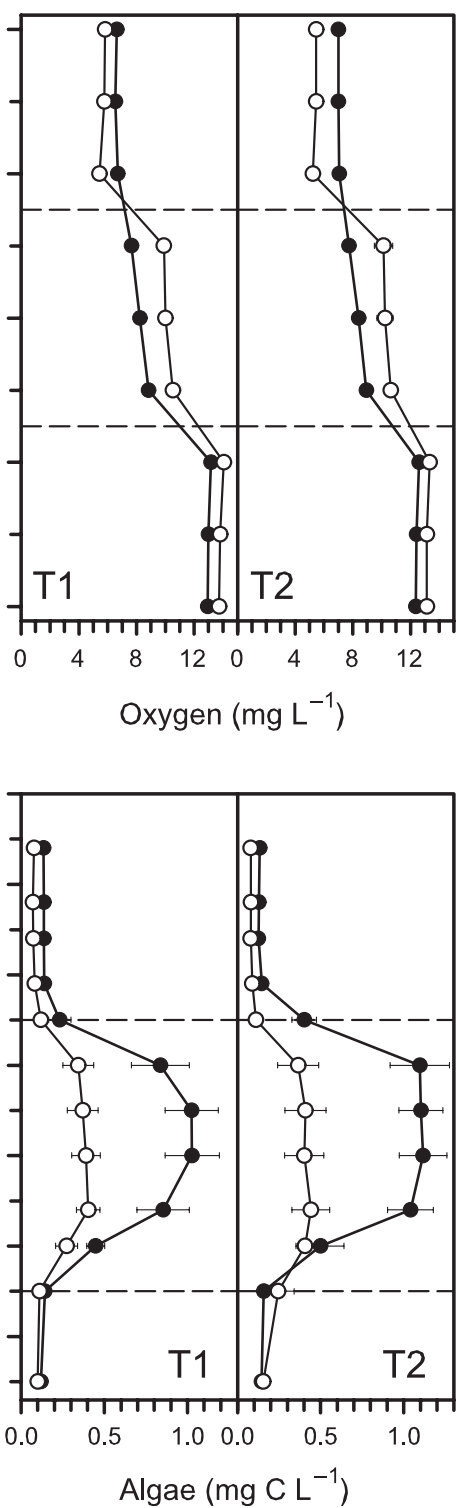

Fig. 2 Vertical profiles of environmental conditions in expts. 1-3. Oxygen and food concentrations (mean \pm SE, $n=3$ ) in the pre-fish period (open symbols) and in the fish period (closed symbols) in the two towers (T1 and T2). The horizontal broken lines indicate the thermoclines.

one tower was already too low to calculate a reasonable distribution. This resulted in together 35 daytime profiles of nine vertical samples each for three experiments. In addition, night samples ( $3 \mathrm{~h}$ after light-off) were taken in expts. 2 and 3 at the same dates as the day samples (46 profiles).

\section{Statistics}

As the total number of Daphnia per tower varied temporally and between towers, the profiles were expressed as percentage of the total population at each depth. To calculate the total population size, counts at each sampling port were integrated vertically considering the distances between ports and the respective water volume.

All statistical analyses were performed with the NCSS statistical package (Hines, 2000). To characterise the vertical distribution patterns of Daphnia, we used the technique developed for the Plankton Towers by B. F. J. Manly as described in detail in Lampert et al. (2003). The 35 (23) non-transformed Daphnia percentages obtained from each sampling depth were subjected to a principal component analysis (PCA) based on the covariance matrix. The principal components reflect different aspects 
of the distribution in terms of contrast between the percentages at different depths. Successive PCs add to the explanation of the total variation, that is, the first few PCs can be used to describe the main aspects of the depth distributions.

We choose sufficient principal components to account for c. $90 \%$ of the total variation of the data. These PCs were analysed further to relate them to the experimental factors. A general linear model ANOVA on the factor scores of the PCs explaining most of the variation was used to estimate the importance of the main effects (experiment, tower, presence of fish and Daphnia size) and the two-way interactions between them. The ANOVA identified the experimental factors that were related to different aspects (PCs) of the distribution, that is, the factors that modified the shape of the distribution. This is more instructive than the comparison of parameters reducing the distribution to a single value (e.g. the mean depth).

Data to compare the distributions during day and night were only available for two of the three experiments. To assess the effect of light, we performed the identical statistical procedure, but only for expt. 2 and 3, and with the factor 'light' instead of 'size'. The two size classes were pooled as we found no significant fish $\times$ size interaction in the full analysis.

\section{Results}

\section{Environmental factors}

Vertical profiles of environmental factors in the three experiments are plotted in Figs. 1 \& 2. The small error bars for temperature and oxygen demonstrate that fish activity had no effect on the stratification of these environmental factors in expts. 1 and 2. Temperature profiles were very stable and identical in all experiments and in both towers as this was the preset, electronically regulated factor. Note that the profile shown in Fig. 1 is composed of 36 measurements ( 6 sampling dates $\times 2$ towers $\times 3$ experiments), and the error bars are invisible as they are smaller than the symbols.

Oxygen concentrations (Fig. 2) were also stable, but some differences between the two towers were unavoidable. We were successful in establishing the vertical profiles as attempted, that is, hypoxic conditions $\left(<1 \mathrm{mg} \mathrm{L}^{-1}\right)$ in the hypolimnion in expts. 1 and 2 and oxic conditions in the deep layers in expt. 3. The deviation of the pre-fish profile in expt. 1 (tower 1) was attributed to slightly elevated oxygen levels at the beginning of the experiment. Turbulence caused by swimming activity of fish would have transported oxygen across the thermocline, resulting in higher oxygen concentrations at $3 \mathrm{~m}$ depth in the fish treatments. This was not found; rather, the oxygen concentrations at $3 \mathrm{~m}$ depth did not change or decreased slightly in the fish treatments. On the contrary, fish being able to penetrate the hypolimnion in expt. 3 probably had some effect on oxygen stratification. Because of decreasing temperatures, the oxygen concentrations in the pre-fish period increased with depth, but the difference between the upper two strata vanished when fish were present. However, these differences should not affect the Daphnia behaviour as the oxygen concentration was never below $5 \mathrm{mg} \mathrm{L}^{-1}$. Being a pond species, $D$. pulicaria can regulate its respiratory rate above $50 \%$ oxygen saturation (Lampert, 1984). However, near the critical oxygen level $\left(<1 \mathrm{mg} \mathrm{O}_{2} \mathrm{~L}^{-1}\right)$, small differences between the towers may have an effect on the vertical distribution of Daphnia.

Maintenance of stable food concentrations was more difficult, as algal abundance changed temporally owing to growth, sinking losses and grazing. Hence, we had to monitor the algal concentration and estimate the amount of algae to be replaced everyday. Consequently, there was more variability in the food profiles. Algal data presented in Fig. 2 are the measurements taken in the morning at the time of zooplankton sampling, and before new algae were added. The actual food concentrations during the following $24 \mathrm{~h}$ in the hypolimnion, and in the epilimnion of expt. 2, were eventually higher. The differences between hypolimnetic algal concentrations can be explained by Daphnia grazing. Daphnia mortality owing to fish predation was low in expt. 1 with a hypolimnetic oxygen refuge but was very high in expt. 3, while it was intermediate in expt. 2 (Larsson \& Lampert, 2011). Consequently, the Daphnia biomass grazing in the hypolimnion was high in the presence of fish (cf. Fig. 3) but lower in the absence of fish, that is, the remaining algal concentrations in the morning were higher under no-fish conditions. In contrast, grazing was very high in expt. 3 without fish, but was very low when fish eliminated Daphnia, which resulted in low morning algal concentrations in the absence of fish. Nevertheless, the attempted profiles of food concentration were obtained as daily averages. In the hypolimnion, the food availability exceeded the incipient limiting Scenedesmus concentration (ILC), where the feeding rate becomes maximal for D. pulicaria (c. $0.4 \mathrm{mg} \mathrm{C} \mathrm{L}^{-1}$; Lampert, 1987), while food was strongly limiting in the epilimnion of expts. 1 and 3.

\section{Daphnia distribution}

The Daphnia populations grew to $30000-70000$ per tower in expts. 1 and 2, and to 98000 in expt. 3 before fish 

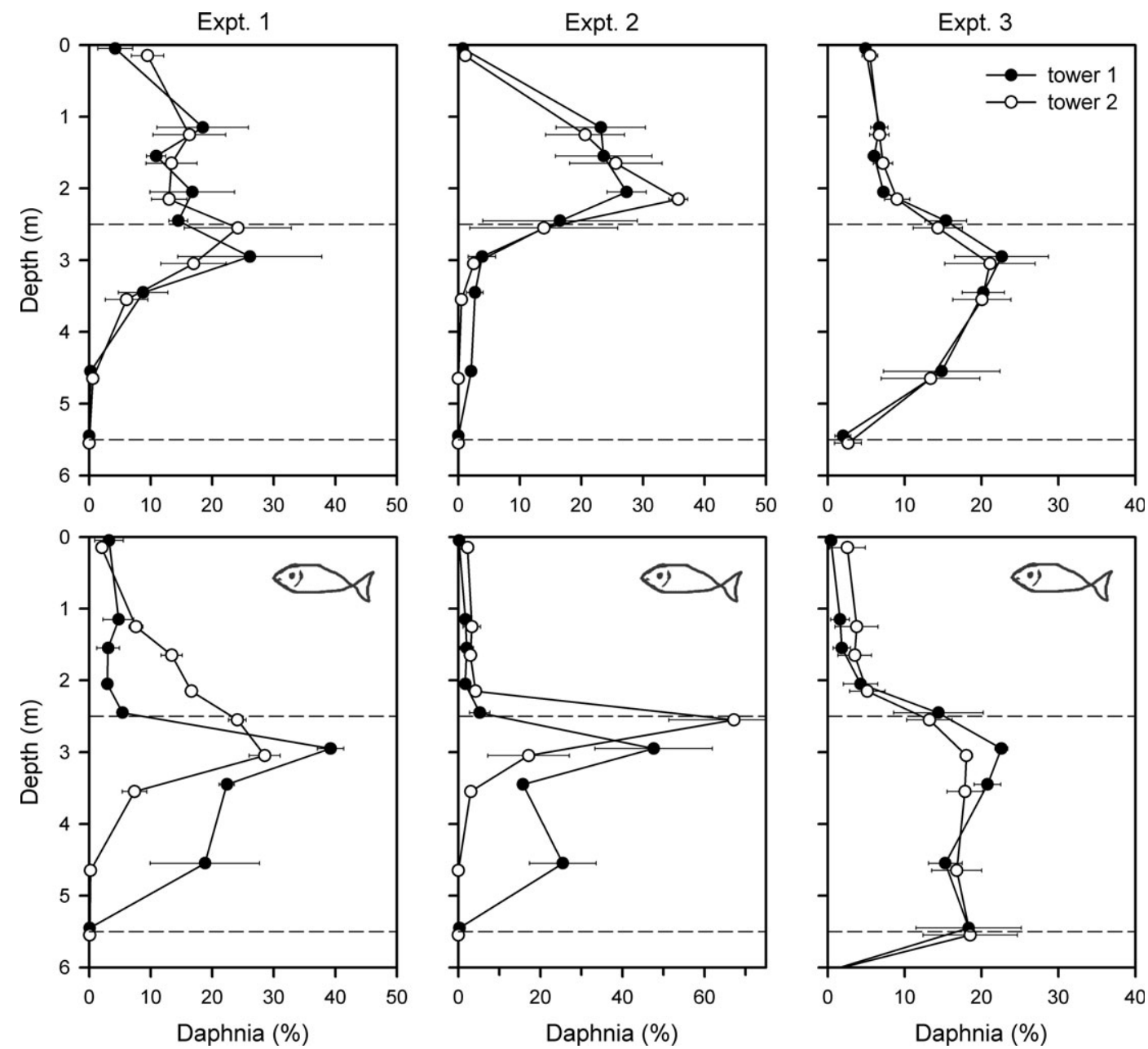

Fig. 3 Relative vertical distributions of the total Daphnia population during the day in three experiments and two towers (mean $\pm \mathrm{SE}, n=3$ ). The pictogram designates the presence of fish. For the environmental conditions in the three experiments refer to Fig. 2.

introduction, and they declined at differing rates after the fish had been introduced (Larsson \& Lampert, 2011). The vertical distributions of the total population of $D$. pulicaria in response to the experimental conditions are depicted in Fig. 3. There are striking differences between experiments as well as in the absence and presence of fish.

Before the introduction of fish, Daphnia distributed according to the relative suitability of the habitat as predicted by an IFD with costs (Lampert et al., 2003) balancing the availability of food against hypolimnetic costs. The hypolimnetic costs in expt. 3 represent only low temperatures, while hypoxia adds to the costs in expts. 1 and 2. Consequently, the distributions shifted upwards in expts. 1 and 2 compared to expt. 3. Nearly all Daphnia were found in the epilimnion in expt. 2 as it contained sufficient food, and there would only have been disadvantages to entering the cold, hypoxic hypolimnion.

The introduction of fish had a strong effect in all experiments as Daphnia moved into the hypolimnion to avoid fish predation. The downward migration was restricted to the upper part of the hypolimnion by hypoxia in expts. 1 and 2, but Daphnia distributed homogeneously in the hypolimnion if oxygen was available (expt. 3).

Figure 3 compares the results of the two mesocosms. The distributions in the towers were rather similar in all experiments before the introduction of fish, and in expt. 3 also in the presence of fish. However, although the general effect of fish on the distribution was the same in expts. 1 and 2, the vertical profiles seemed to differ between the towers particularly in the hypolimnion.

\section{Statistical analysis of the Daphnia distribution}

We subjected the full data set (percentages at nine sampling ports) for the daytime samples including the three experiments, the two towers, the presence or absence of fish and two size groups of Daphnia to a PCA to describe the main aspects of the distributions 
Table 1 Principal component analysis of the vertical distribution of Daphnia in the Plankton Towers. Listed are the eigenvectors of the first three principal components (PC1-PC3) accounting for $87 \%$ of the total variation (bottom line)

\begin{tabular}{llcc}
\hline Depth (m) & PC1 & PC2 & PC3 \\
\hline 0.1 & 0.015 & -0.032 & -0.016 \\
1.2 & 0.330 & 0.209 & -0.169 \\
1.6 & 0.359 & 0.207 & -0.175 \\
2.1 & $\mathbf{0 . 4 4 0}$ & 0.147 & -0.161 \\
2.5 & 0.175 & $-\mathbf{0 . 8 8 3}$ & 0.205 \\
3.0 & $-\mathbf{0 . 5 6 9}$ & -0.130 & $-\mathbf{0 . 6 5 7}$ \\
3.5 & -0.337 & 0.108 & 0.049 \\
4.6 & -0.293 & 0.263 & $\mathbf{0 . 5 3 8}$ \\
5.5 & -0.120 & 0.114 & 0.387 \\
Cumulative & 44.7 & 71.3 & 87.4 \\
variance (\%) & & & \\
\hline
\end{tabular}

Bold numbers highlight major contrasts. The main thermocline is located at the depth of $2.5 \mathrm{~m}$ (cf. Fig. 1).

(Table 1). The first three principal components (PC1-PC3) explain more than $87 \%$ of the variance. The largest proportion $(47 \%)$ is explained by the PC1 alone. PC1 reflects mainly a contrast between the ports above and below the thermocline located at $2.5 \mathrm{~m}$ depths. PC2 indicates a strong contrast within the thermocline. The contrast detected by $\mathrm{PC} 3$ reflects a shift within the hypolimnion.

Table 2 presents the results of the ANOvAs on PC1 and PC2. All four main effects are highly significant for PC1. There are also significant two-way interactions except in all combinations with 'size'. PC2 shows the same pattern of significant effects and interactions as PC1, except that 'size' as a main effect is no longer significant. We do not present the ANOVA results on PC3 as it makes only a minor contribution to the total variance. Only the factors experiment $(P<0.01)$ and fish $(P=0.042)$ were significant.
Although the two towers were supposed to be replicates, we found significant tower effects as well as significant interactions for 'tower' with 'experiment' and 'fish'. This is consistent with the conclusions drawn from the inspection of Fig. 3. As the distributions differed between the two towers only in expts. 1 and 2 after fish introduction, we suspect that they were influenced by factors that we could not perfectly control, such as small differences in the hypolimnetic oxygen concentrations. A closer inspection of the fine structure of the oxygen profiles revealed differences (Fig. 4). Although these differences were small, they are in the critical range for survival of D. pulex (Larsson \& Lampert, 2011) around 0.5-0.7 $\mathrm{mg} \mathrm{O}_{2} \mathrm{~L}^{-1}$. The hypolimnetic Daphnia distributions in Exp. 2 may be explained by oxygen, as the concentrations were clearly higher in tower 1, allowing Daphnia to enter deeper layers to avoid fish. However, the situation seemed to be more complex in expt. 1, where oxygen concentrations differed only in the deepest layer, but the shape of the Daphnia distributions differed also in the epilimnion.

Body size is a significant main effect for PC1 but not for further principal components. There were no two-way interactions, which indicates that size matters under all conditions even in the absence of fish. Hence, we pooled the two towers to plot the size-dependent distributions (Fig. 5). In the absence as well as in the presence of fish, large Daphnia dwelled deeper in the food-rich hypolimnion in expts. 1 and 3 but not in expt. 2, where food was also abundant in the epilimnion.

\section{The effect of light}

Day and night samples were only available for expts. 2 and 3 (Fig. 6). Therefore, we subjected the reduced data

Table 2 Results of a GLM ANOVA on the factor scores of PC1 and PC2 with estimates of the main effects of experiment (exp), tower (tow), presence of fish (fish), Daphnia body size (size) and the two-way interactions between these

\begin{tabular}{|c|c|c|c|c|c|c|c|}
\hline \multirow[b]{2}{*}{ Factor } & \multirow[b]{2}{*}{ d.f. } & \multicolumn{3}{|l|}{ PC1 } & \multicolumn{3}{|l|}{ PC2 } \\
\hline & & MS & $F$ & $P$ & MS & $F$ & $P$ \\
\hline Tow & 1,46 & 6.20 & 28.42 & $<0.001^{*}$ & 9.53 & 19.67 & $<0.001^{*}$ \\
\hline Fish & 1,46 & 16.83 & 77.16 & $<0.001^{*}$ & 5.16 & 10.67 & $0.002^{*}$ \\
\hline Size & 1,46 & 2.10 & 9.61 & $0.003^{*}$ & 1.08 & 2.24 & 0.141 \\
\hline Exp $\times$ size & 2,46 & 0.64 & 2.94 & 0.063 & 0.41 & 0.85 & 0.435 \\
\hline Tow $\times$ fish & 1,46 & 3.15 & 14.45 & $<0.001^{*}$ & 4.23 & 8.73 & $<0.001^{*}$ \\
\hline Tow $\times$ size & 1,46 & 0.03 & 0.14 & 0.706 & 0.64 & 1.32 & 0.257 \\
\hline Fish $\times$ size & 1,46 & 0.08 & 0.35 & 0.559 & 0.44 & 0.90 & 0.346 \\
\hline
\end{tabular}

Asterisk denotes significant results. 


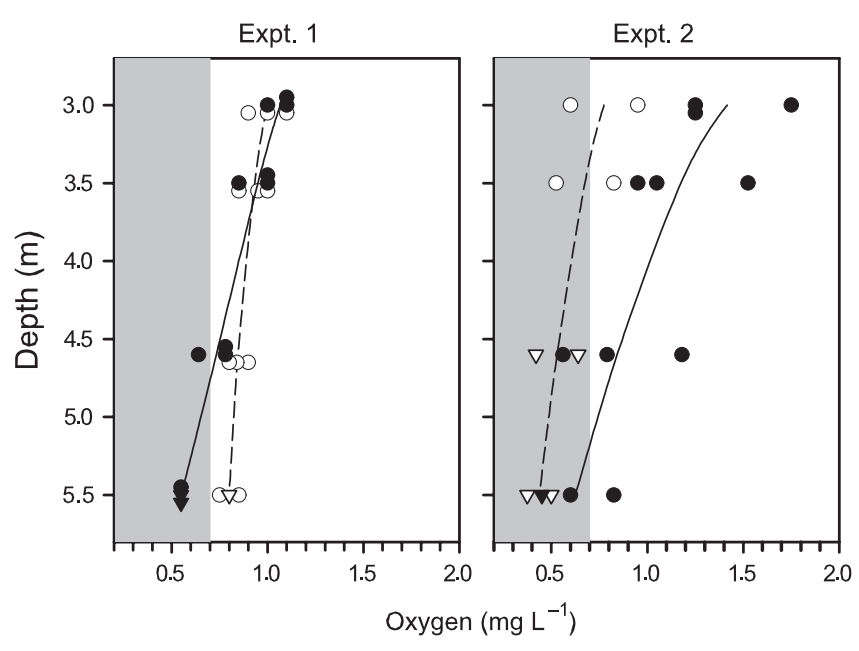

Fig. 4 Fine structure of the vertical oxygen concentration in the hypolimnion of both towers in expts. 1 and 2. Symbols represent individual measurements of oxygen on the sampling days after fish introduction (closed symbols: tower 1, open symbols: tower 2). Zooplankton was sampled immediately after the oxygen measurements. Triangles indicate zooplankton samples that contained no Daphnia. Lines connect mean oxygen concentrations. The shaded area delimits oxygen concentrations below $0.7 \mathrm{mg} \mathrm{L}^{-1}$.

set to a new PCA. The results are very similar to those for the full data set. The first three principal components explained $88.3 \%$ of the variance. We do not present the details here. The PCA was again followed by a GLM ANOVA on the factor scores including experiment, fish, tower and time of the day (light) as main effects. As with the full data set, the effects of experiment, fish, tower and all their two-way interactions were significant. However, there was no significant effect of light $\left(F_{1,30}=0.24\right.$, $P=0.630$ ), and there was only a marginally significantly 'fish $\times$ light' interaction $\left(F_{1,30}=4.63, P=0.040\right)$.

\section{Discussion}

In support of our hypothesis, the results of all experiments can be interpreted as IFDs with costs (Tyler \& Gilliam, 1995). Daphnia showed vertical distributions, that is, not all individuals stayed at the same depths where the relative fitness was maximal. This is consistent with the IFD theory; it reflects density-dependent effects as well as incomplete knowledge of the individual about the local habitat quality in the total environment. A summary of experimental and field studies with Daphnia related to the IFD theory has recently been given in Chapter 5 of Lampert (2011).

In the absence of fish, Daphnia distribute as predicted by the IFD with costs (Lampert et al., 2003; Kessler \& Lampert, 2004a), but the additional costs of hypolimnetic oxygen depletion truncate the distributions in the hypolimnion.
The effect of food is to be seen when comparing expt. 1 with expt. 2. If food is available in the epilimnion and in the hypolimnion (expt. 2), Daphnia stay exclusively in the warm epilimnion as predicted (Lampert et al., 2003). There is no advantage from entering oxygen-depleted layers. However, if the food concentration is high below the thermocline but is very low in the epilimnion (expt. 1), Daphnia must trade the benefits of food against the costs of low temperature and low oxygen concentration. Consequently, part of the population can be found below the thermocline. The effect of oxygen depletion is particularly clear in the comparison of expt. 1 with expt. 3 where a large proportion of the population can be found in the hypolimnion. The distributions in expt. 1 and expt. 2 can also be compared with the figures given in Lampert et al. (2003). This paper predicted a proportion of $60 \%$ of the total Daphnia population dwelling below the thermocline for a hypolimnetic food maximum and a temperature difference of $10{ }^{\circ} \mathrm{C}$. The hypolimnetic proportion in expt. 1 of the present work (cf. Fig. 3) is smaller (37\%), which reflects the effect of oxygen depletion. In contrast, the hypolimnetic proportion in expt. 3 is larger than expected (72\%). This can be explained by the higher population density resulting in a downward shift of the population. These vertical profiles resemble in shape and absolute values very much the profiles reported in Lampert (2005) for the highest population densities (c. 100000 Daphnia per tower) that are equivalent to the densities reached in expt. 3 .

Fish predation has often been shown to be a strong factor influencing vertical distributions of zooplankton (Lampert, 2011), for example, in the Plankton Tower system (Loose, 1993; De Meester et al., 1995), in enclosures (Wright \& Shapiro, 1990; Dini \& Carpenter, 1992) and in field studies (Gliwicz, 1986; Leibold \& Tessier, 1991; Ringelberg et al., 1991). In our experiments, the presence of fish overrules all other factors except very low oxygen concentration, that is, Daphnia leave the epilimnion almost completely to avoid predation. It seems that fish do not like to cross the $10^{\circ} \mathrm{C}$ temperature drop at the upper thermocline. In expt. 1 and expt. 2, severe oxygen depletion limits the depth distribution; hence, Daphnia accumulate near the thermocline. But if oxygen is available (expt. 3), the population spreads out over the whole hypolimnion between the two thermoclines. Note that habitat suitability is rather equally distributed between the thermoclines. Additional costs of going deeper are only related to a longer swimming distance to the warm epilimnion. As fish cause evidently higher costs in the epilimnion than the benefits owing to temperature increase, the homogeneous distribution between the thermoclines reduces intraspecific competition and is in 

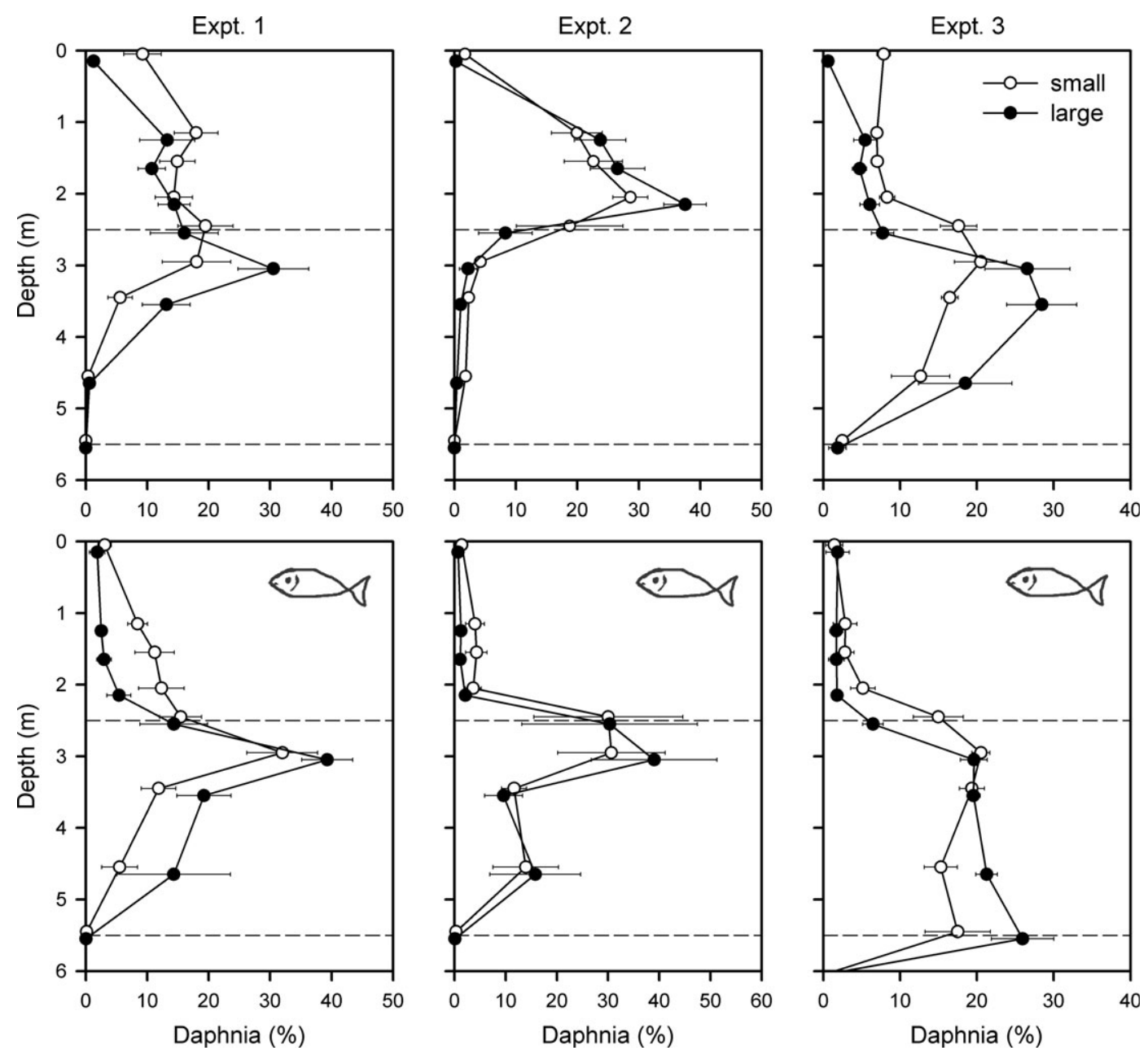

Fig. 5 Relative vertical distributions of two Daphnia size classes during the day (both towers combined) in the three experiments (mean \pm SE, $n=6$ ). The pictogram designates the presence of fish. For the environmental conditions in the three experiments refer to Fig. 2.

accordance with the theory. Crossing the second thermocline would not result in more protection from fish but would cause additional costs $\left(2{ }^{\circ} \mathrm{C}\right.$ temperature decrease). Consequently, Daphnia do not go deeper.

The two towers were designed as replicates; hence, we did not expect differences between vertical distributions within the experiments. However, the ANOv A identified a significant overall tower effect as well as significant 'tow $\times \exp ^{\prime}$ and 'tow $\times$ fish' interactions. Inspection of Fig. 3 reveals that the tower effect is based exclusively on the profiles in the presence of fish in expts. 1 and 2. The two-way interactions hint at factors that we were not able to control perfectly: 'exp' includes the oxygen concentration in the hypolimnion, while 'fish' is related to the fish activity rather than the mere presence of fish. We reduced the hypolimnetic oxygen concentration in expts. 1 and 2 at the start of an experiment, but we could not further control oxygen after the introduction of Daphnia. Although the oxygen profiles were very similar, small hypolimnetic differences developed between towers in expt. 2 (Fig. 2). Also, we aimed to introduce the same number of similarly sized fish into each tower, but we are not sure that fish predation activity matched perfectly. Consequently, we can only explain the differences in hypolimnetic Daphnia distributions between the towers by indirect evidence.

The small differences in oxygen availability may be important as the concentrations are close to the minimum concentrations (c. $0.7 \mathrm{mg} \mathrm{L}^{-1}$ ) tolerated by D. pulicaria (Weider \& Lampert, 1985; Larsson \& Lampert, 2011). The hypolimnetic oxygen fine structure (Fig. 4) reveals small differences between towers in expt. 1, and the majority of points (except at the greatest depths) had oxygen concentrations above $0.7 \mathrm{mg}$. Hence, it is unlikely that oxygen differences are responsible for the different distributions of Daphnia in the towers. On the contrary, oxygen differences are pronounced in expt. 2. Most Daphnia in tower 1 experience $\mathrm{O}_{2}$ concentrations above $0.7 \mathrm{mg} \mathrm{L}^{-1}$, even between 1.0 and $1.5 \mathrm{mg} \mathrm{L}^{-1}$, while in tower 2 all 

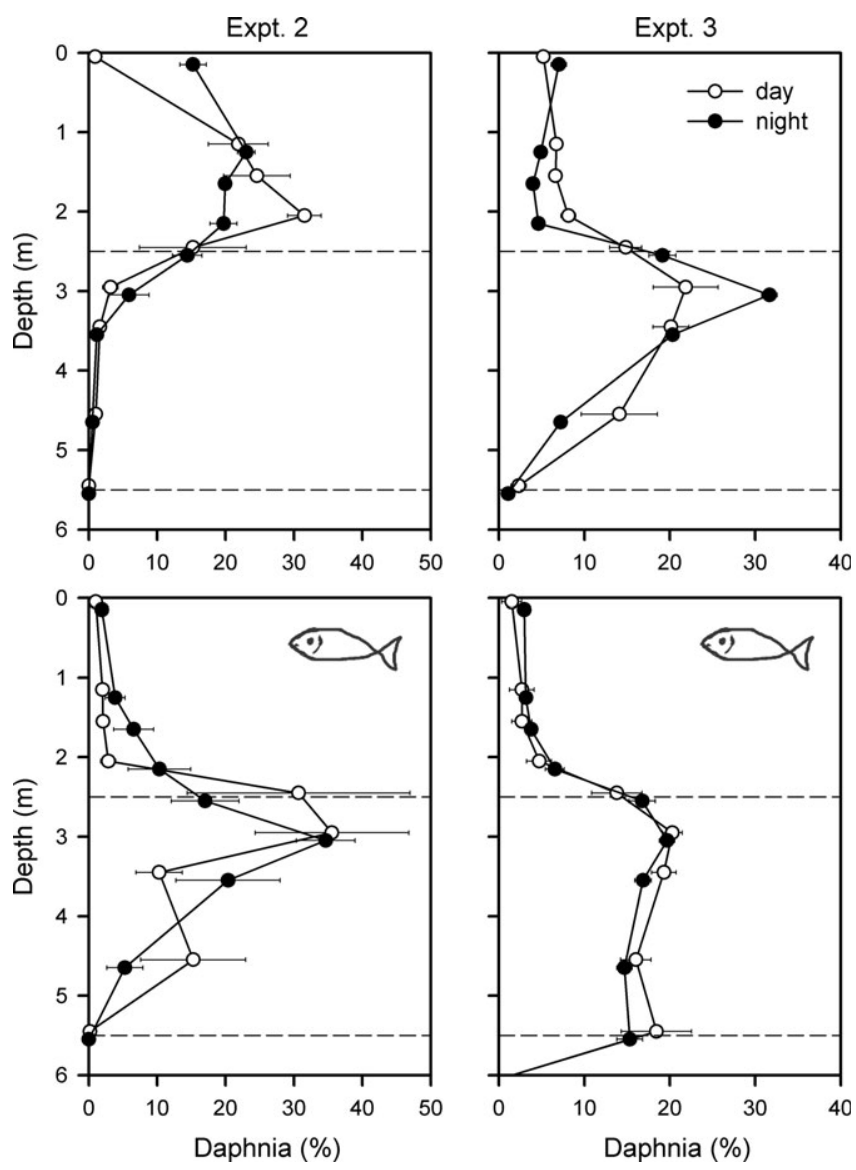

Fig. 6 Comparison of the relative vertical distributions of the total Daphnia population during day and night (both towers combined) in two experiments (mean $\pm \mathrm{SE}, n=6$ ). Values of some error bars are too small to be visible. The pictogram designates the presence of fish. For the environmental conditions in the three experiments refer to Fig. 2.

measurements below $4.5 \mathrm{~m}$ depth (and 2 of 4 measurements above $4 \mathrm{~m}$ ) were lower than the tolerable concentration of $0.7 \mathrm{mg} \mathrm{L}^{-1}$. Consequently, no Daphnia were found below $4 \mathrm{~m}$ depth in tower 2 , and few at 3 and $3.5 \mathrm{~m}$. The greatest part was concentrated in the thermocline between the threats of fish and oxygen depletion, which is consistent with the hypothesis of oxygen causing the differing hypolimnetic distributions of Daphnia in expt. 2. In the presence of fish, Daphnia left the epilimnion almost completely in both towers in expt. 2, which indicates that fish activity was high in both towers. However, in expt. 1 the epilimnetic distributions differed between towers. In tower 1 the numbers of Daphnia were strongly reduced from the surface to the thermocline, while some part of the Daphnia population in tower 2 remained above the thermocline despite the presence of fish. This seems to be indirect evidence of lower fish predation in tower 2 compared with tower 1 . Besides unintended differences in fish biomass, activity or behaviour, a lower predation rate can also result from lower Daphnia sizes, as fish are more efficient preying on large Daphnia. In fact, the size distribution of Daphnia in tower 1 was skewed toward smaller individuals $(70 \%$ in the small size groups) compared with tower $2(55 \%)$. This was unusual as there were no differences between towers in expts. 2 and 3 (35 versus $38 \%$ and 73 versus $74 \%$, respectively).

Visual predation by fish is related to prey size (conspicuousness) and light (Eggers, 1982; O'Brien, 1987). Hence, we expected to find differences in the vertical distributions of differently sized Daphnia in the presence of fish during the day as well as between day and night. This is the basis of predator avoidance as the ultimate cause of diel vertical migration (reviewed in Lampert, 2011). Therefore, we included two size groups of Daphnia in the analysis of the distributions. The significant main effect of size, but the absence of any significant two-way interaction of size, indicates that small and large individuals behave differently independent of the presence of fish. Inspection of Fig. 5 reveals that large Daphnia stay deeper than small ones in four of six scenarios (expts. 1 and 3), but no clear difference can be seen in expt. 3. This is consistent with the results of Kessler \& Lampert (2004b) where Daphnia traded only temperature for food in the absence of fish. They concluded that temperature was more important for the development of juvenile Daphnia, but food was the more important factor for adults. Although they did not test the scenario of our expt. 2, our result (no difference between sizes) fits the expectations as there is no trade-off in the epilimnion without fish, that is, fitness is highest there for all sizes.

The absence of a significant main effect of light was unexpected as light is the factor driving diel vertical migration (Ringelberg, 2010). However, the marginally significant 'fish $\times$ light' interaction may hint at some small differences to be seen in Fig. 6. In expt. 2, Daphnia avoided the immediate surface layer and accumulated in the lower epilimnion during the day. At night they distributed equally in the epilimnion as food and temperature were rather homogeneously distributed. Hence, the daytime avoidance of the surface must be a direct light effect. On the other hand, in the presence of fish Daphnia did not return to the warm epilimnion at night as expected. We assume that the fish biomass in our experiment (c. $26 \mathrm{~g} \mathrm{~m}^{-2}$ ) was relatively high compared with natural systems (e.g. $23 \mathrm{~g} \mathrm{~m}^{-2}$ in the very productive Loch Leven; Morgan, 1980). Restriction of fish to the epilimnion and the stability of the water column probably caused a high concentration of kairomone in the warmer water, and in 
combination with mechanical clues of the moving fish, the stimulus was probably sufficiently large to prevent Daphnia from moving upwards at night and profiting from the higher temperatures. Earlier experiments looking at fish effects in the tower system (Loose, 1993; De Meester et al., 1995) provided food only in the epilimnion; hence, Daphnia moving upwards at night profited from both food and high temperatures. In the present experiments, there was no food shortage in the hypolimnion, and hence less incentive for Daphnia to enter risky waters at night (Vos et al., 2002). This is consistent with field results from eutrophic lakes with high hypolimnetic seston concentrations where Daphnia did not return to surface waters at night (Pijanowska \& Dawidowicz, 1987; Gliwicz \& Pijanowska, 1988).

In summary, this study expanded the theory of depth distribution of zooplankton. The addition of other environmental factors revealed that the distribution can be explained by the vertical distributions of relative fitness. Evidently, fish predation has an overriding effect, at least for large zooplankton like D. pulicaria. We did not produce any combination of other environmental factors that would motivate Daphnia to take the risk of severe fish predation mortality. In that respect, oxygen depletion is not necessarily a factor reducing fitness. As Daphnia are usually more tolerant than fish to low-oxygen conditions, they can accumulate in a transition layer where oxygen is low, but hydrogen sulphide has not yet developed. Predation mortality of Daphnia in our expt. 3 was significantly higher than in the experiments with a hypoxic hypolimnion, which demonstrates that oxygen depletion can provide a refuge against fish predation (Larsson \& Lampert, 2011).

\section{Acknowledgments}

We wish to thank various collaborators for help with these laborious experiments. Maren Volquartsen prepared the mass cultures of Daphnia and food algae and measured algal densities with the particle counter. Heike Harre spent several weeks counting samples with the Optical Plankton Counter. Numerous colleagues of the former Max Planck Institute of Limnology helped maintaining the Plankton Towers or contributed to fruitful discussions. Two anonymous referees provided valuable suggestions that improved an earlier version of this paper. We are also grateful to the Max Planck Society for the Advancement of Science for supporting the work of P. L. through a guest researcher fellowship and to the University of Bergen for travel support.

\section{References}

De Meester L., Weider L.J. \& Tollrian R. (1995) Alternative antipredator defences and genetic polymorphism in a pelagic predator-prey system. Nature, 378, 483-485.

Dini M.L. \& Carpenter S.R. (1992) Fish predators, food availability and diel vertical migration in Daphnia. Journal of Plankton Research, 14, 359-377.

Dodson S.I. (1990) Predicting diel vertical migration of zooplankton. Limnology and Oceanography, 35, 1195-1200.

Eggers D.M. (1982) Planktivore preference by prey size. Ecology, 63, 381-390.

Gliwicz Z.M. (1986) Predation and the evolution of vertical migration in zooplankton. Nature, 320, 746-748.

Gliwicz Z.M. \& Pijanowska J. (1988) Effect of predation and resource depth distribution on vertical migration of zooplankton. Bulletin of Marine Science, 43, 695-709.

Hanazato T., Yasuno M. \& Hosomi M. (1989) Significance of a low oxygen layer for a Daphnia population in Lake Yunoko, Japan. Hydrobiologia, 185, 19-27.

Haney J.F. \& Hall D.J. (1973) Sugar coated Daphnia: a preservation technique for Cladocera. Limnology and Oceanography, 18, 331-333.

Havel J.E. \& Lampert W. (2006) Habitat partitioning of native and exotic Daphnia in gradients of temperature and food: mesocosm experiments. Freshwater Biology, 51, 487-498.

Hines J. (2000) NCSS 2000. NCSS Statistical Software, Kaysville, UT, U.S.A.

Johnsen G.H. \& Jakobsen P.J. (1987) The effect of food limitation on vertical migration in Daphnia longispina. Limnology and Oceanography, 32, 873-880.

Kessler K. \& Lampert W. (2003) Counting and sizing preserved Daphnia with the Optical Plankton Counter. Archiv für Hydrobiologie, 156, 485-493.

Kessler K. \& Lampert W. (2004a) Fitness optimization in Daphnia in a trade-off between food and temperature. Oecologia, 140, 381-387.

Kessler K. \& Lampert W. (2004b) Depth distribution of Daphnia in response to a deep-water algal maximum: the effect of body size and temperature gradient. Freshwater Biology, 49, 392-401.

Lampert W. (1984) The measurement of respiration. In: $A$ Manual on Methods for the Assessment of Secondary Productivity in Fresh Waters (Eds J.A. Downing \& F.H. Rigler), pp. 413-468. Blackwell, Oxford.

Lampert W. (1987) Feeding and nutrition in Daphnia. Memorie dell'Istituto Italiano di Idrobiologia, 45, 143-192.

Lampert W. (1993) Ultimate causes of diel vertical migration of zooplankton: new evidence for the predator avoidance hypothesis. Archiv für Hydrobiologie, Beihefte Ergebnisse der Limnologie, 39, 79-88.

Lampert W. (2005) Vertical distribution of zooplankton: density dependence and evidence for an ideal free distribution with costs. BMC Biology, 3, 10. 
Lampert W. (2011) Daphnia: Development of a Model Organism in Ecology and Evolution. International Ecology Institute, Oldendorf/Luhe.

Lampert W. \& Loose C.J. (1992) Plankton towers: bridging the gap between laboratory and field experiments. Archiv für Hydrobiologie, 126, 53-66.

Lampert W., McCauley E. \& Manly B. (2003) Trade-offs in the vertical distribution of zooplankton: ideal free distribution with costs? Proceedings of the Royal Society of London Series B, 270, 765-773.

Lampert W. \& Sommer U. (2007) Limnoecology, 2nd edn. Oxford University Press, New York.

Larsson P. \& Lampert W. (2011) Experimental evidence of a low-oxygen refuge for large zooplankton. Limnology and Oceanography, 56, 1682-1688.

Leibold M.A. (1990) Resources and predators can affect the vertical distributions of zooplankton. Limnology and Oceanography, 35, 938-944.

Leibold M.A. \& Tessier A.J. (1991) Contrasting patterns of body size for Daphnia species that segregate by habitat. Oecologia, 86, 342-348.

Loose C.J. (1993) Daphnia diel vertical migration behavior: response to vertebrate predator abundance. Archiv für Hydrobiologie, Beihefte Ergebnisse der Limnologie, 39, 29-36.

Morgan N.C. (1980) Secondary production. In: International Biological Programme 22: The Functioning of Freshwater Ecosystems (Eds E.D. Le Cren \& R. Lowe-McConnell), pp. 247-340. Cambridge University Press, Cambridge.

O'Brien W.J. (1987) Planktivory by freshwater fish: thrust and parry in the pelagia. In: Predation: Direct and Indirect Impacts on Aquatic Communities (Eds W.C. Kerfoot \& A. Sih), pp. 3-16. University Press of New England, Hanover, N. H.

Pijanowska J. \& Dawidowicz P. (1987) The lack of vertical migration in Daphnia: the effect of homogenously distributed food. Hydrobiologia, 148, 175-181.

Reichwaldt E.S. (2008) Food quality influences habitat selection in Daphnia. Freshwater Biology, 53, 872-883.

Reichwaldt E.S. \& Abrusan G. (2007) Influence of food quality on depth selection of Daphnia pulicaria. Journal of Plankton Research, 29, 839-849.
Ringelberg J. (2010) Diel Vertical Migration of Zooplankton in Lakes and Oceans. Springer, Dordrecht.

Ringelberg J., Flik B.J.G., Lindenaar D. \& Royackers K. (1991) Diel vertical migration of Daphnia hyalina (sensu latiori) in Lake Marseveen: part. 1. Aspects of seasonal and daily timing. Archiv für Hydrobiologie, 121, 129-145.

Tessier A.J. \& Leibold M.A. (1997) Habitat use and ecological specialization within lake Daphnia populations. Oecologia, 109, 561-570.

Tyler J.A. \& Gilliam J.F. (1995) Ideal free distributions of stream fish: a model and test with minnows, Rhinicthys atratulus. Ecology, 76, 580-592.

Vanderploeg H.A., Ludsin S.A., Cavaletto J.F., Höök T.O., Pothoven S.A., Brandt S.B. et al. (2009) Hypoxic zones as habitat for zooplankton in Lake Erie: refuges from predation or exclusion zones? Journal of Experimental Marine Biology and Ecology, 381, S108-S120.

Vos M., Flik B.J.G., Vijverberg J., Ringelberg J. \& Mooij W.M. (2002) From inducible defences to population dynamics: modelling refuge use and life history changes in Daphnia. Oikos, 99, 386-396.

Weider L.J. \& Lampert W. (1985) Differential response of Daphnia genotypes to oxygen stress: respiration rates, hemoglobin content and low-oxygen tolerance. Oecologia, 65, 487-491.

Williamson C.E., Fischer J.M., Bollens S.M., Overholt E.P. \& Breckenridge J.K. (2011) Towards a more comprehensive theory of zooplankton diel vertical migration: integrating ultraviolet radiation and water transparency into the biotic paradigm. Limnology and Oceanography, 56, 1603-1623.

Winder M., Spaak P. \& Mooij W.M. (2004) Trade-offs in Daphnia habitat selection. Ecology, 85, 2027-2036.

Wright D. \& Shapiro J. (1990) Refuge availability: a key to understanding the summer disappearance of Daphnia. Freshwater Biology, 24, 43-62.

(Manuscript accepted 23 August 2012) 